\title{
The Approach on Influence of Biasing Circuit in Wideband Low Noise Amplifier to Evaluate Robustness Performance
}

\author{
Kishor G Sawarkar ${ }^{1}$, Kushal Tuckley ${ }^{2}$ \\ ${ }^{1}$ Research Scholar at MCT's RGIT \\ ${ }^{2}$ Adjunct Professor at IIT, Bombay \\ ${ }^{1,2}$ Mumbai, Maharastra, India
}

\author{
Pramod K B ${ }^{3}$, Kumaraswamy H.V ${ }^{4}$ \\ ${ }^{3} \mathrm{Ph}$.D. Student of Jain University \\ ${ }^{3}$ Assistant Professor at MCT's RGIT \\ ${ }^{4}$ Department of Telecommunication \\ ${ }^{4}$ R. V. College of Engineering, Bangalore, India
}

\begin{abstract}
This proposed work investigates the effects of biasing circuit in the ultra-wideband microwave low noise amplifier which operates between $3 \mathrm{GHz}$ to $10 \mathrm{GHz}$. The complete circuit is visualized the importance of every component in the design with respect to linear measurements like Gain, Noise Figure, Return loss under unconditionally stable condition. The design and realization are made by using Hybrid Microwave integrated circuit in AWR microwave office. The thing that is absolutely necessary and frequently the difficult step in the design of an LNA is 'biasing circuit design'. The difficulty situation arises because traditional methods LNA by using $S$-parameters data files in EDA tools provides almost all linear measurements. Hence a number of time consuming iterations of different biasing circuits with optimization methods may be required to reach targeted specifications with the fixed operating point at the desired points in the load line. Considering this behavior, various alternate biasing circuit schemes are prepared and founded the results associated with it. Furthermore, this paper unmistakably clarifies the impacts of the biasing circuit by utilizing intermodulation and harmonics distortion technique for portrayal characterization. Different cases and sorts of the biasing circuits with various biasing focuses have been tested and given clear perspective of the biasing ideas.
\end{abstract}

Keywords- PHEMT, Biasing Networks, AWR microwave office, Impedance matching, HMIC and LNA

\section{INTRODUCTION}

Advancing in the wireless communication networks it has been arise the set of circumstances found that design of Microwave circuits should meet various parameters at a time with good performance. In case of LNA the parameters like Bandwidth, Gain, Noise figure and return loss should all meet the specifications at the same time eventually all those parameters with not work with each other favors. To meet at the specifications with the help of theoretical equations and majorly the tuners in the commercial software EDA tools like AWR Microwave office, ADS, HFSS etc. are made quite easier for microwave circuit designing.
[5] In contrast, hybrid MIC circuits using discrete components and distributed elements occupy more area and dissipate more power. However, hybrid MIC technologies provide a shorter design time, capabilities of customization and fine tune of fabricated circuits. Also, Optimization of the variables becomes quite easy.

In this paper, authors present effects of biasing in the LNA which includes design optimization and analysis of matching networks and various bias circuits and variation of their effects in primary circuit are explained. [6] To satisfy high gain, LNA is designed by using cascade topology and to achieve maximum power transfer, impedance matching is essential for proper gain and NF with VSWR. Some of network to build impedance matching uses lump element, micro strip line or combination of such elements. Many design of LNA have been conducted and proposed to satisfy high gain and good impedances matching network using lump element or micro strip line and some of characteristic design has been obtained at the defined frequency and application. For all circuit design the industrial standard AWR microwave office tool is used, also to optimize micro strip line and impedance matching to determine trade off value of gain, Noise Figure, return loss and voltage standing wave ratio (VSWR).

This paper is organized as follows. The research background which is composed of recently published articles with respect to biasing circuits in microwave is described in Section II, the design of the low-noise amplifier with different bias circuit is presented in Section III, the LNA performance under limited set exposures with results are discussed in Section IV and finally the conclusive remarks are drawn in the last section.

\section{RESEARCH BACKGROUND}

This segment examines distributed data about biasing circuit in microwave circuits, additionally, their estimations techniques and investigation. [7] In their work, presented a balun low noise amplifier (LNA) in which the noise figure (NF) and power consumption are reduced by using a feedback 
biasing structure. The circuit was based on a conventional wideband balun LNA with noise cancellation. In which they replaced the typical current source of the CG stage by a transistor that established a feedback loop in that stage. [8] introduced linearity change of a $10 \mathrm{~W}$ GaN HEMT PA utilizing a dynamic entryway biasing procedure for smoothing an exchange period of the PA as indicated by the quick information power. Zhang, Ma, Yu, \& Li, [9], exhibited a dynamic biasing circuit was inserted in the chip which mitigates the deviation of biasing point, enhances the solidness and consistency of execution. Both noise and small signal measurements are performed on-wafer. Ghosh \& Srivastava, [10], gave the symmetric design biasing system, which makes the structure polarization uncaring not at all like which was accounted for active frequency-selective surface(AFSS). Harzheim, Heuermann, \& M. Marso,[11], displayed a versatile biasing strategy for step recuperation diode based brush generators which was controlled by a product schedule. The point was to give the most extreme conceivable consonant yield power for a given arrangement and diverse information frequencies amid info power variety.

\section{A. Hypothesis behind the Biasing Circuits}

With the thought of practical bias ways for inclination of transistors. Contrasted with design practice at lower frequencies, fitting biasing expressions are more constrained RF and microwave since it is hard to keep the biasing circuit's parasitic from connecting with the signal path way at microwave frequencies [12-14].

\section{B. $\quad$ Bias Circuits and its Instabilities}

Once the microwave LNA is composed, it stays to give the dc bias voltages and currents required for the dynamic active device. This is no straightforward issue, as the courses of action to present the biases can aggravate the microwave circuit. By and large, high impedance miniaturized micro strip follows can be utilized as decoupling inductors, yet alert must be practiced not to make a low frequency oscillator circuit in the predisposition bias network system.

A typical reason for inconvenience is the utilization of an inductor with a huge bypass capacitor, which can make a resonator in the $\mathrm{GHz}$ region that can bolster oscillation of the active components, which will have high gain at lower frequencies.

Bias-circuit instabilities are a common source of problems in amplifiers and other active circuits. These for the most part result from the utilization of inductors and capacitors in the Bias-circuit without respect to resonances or circumstances where $180^{\circ}$ stage movement can happen.

\section{LNA DESIGN AND ANALYSIS}

LNA parameters are mainly depend on $S$ parameters which varies with respect to frequency. Also $\Gamma$ in depends on Zin and $\Gamma_{\mathrm{L}}, \Gamma_{\mathrm{L}}$ depends on $\mathrm{Z}_{\mathrm{L}}$ and $\Gamma_{\mathrm{IN}}$. Zin and $\mathrm{Z}_{\mathrm{L}}$ will be different for different biasing components. Effects of biasing components is also frequency dependent.

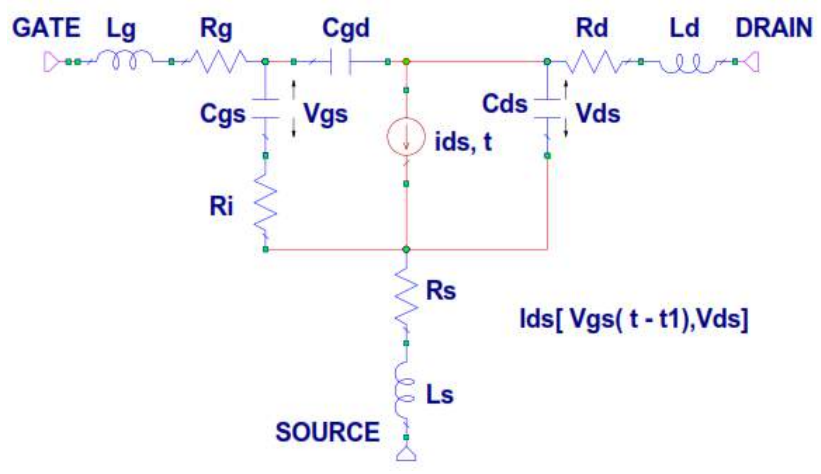

Figure 1. The small signal model of a pHEMT

Cgs and Cgd depends on the biasing voltage because the depletion region changes with the bias .

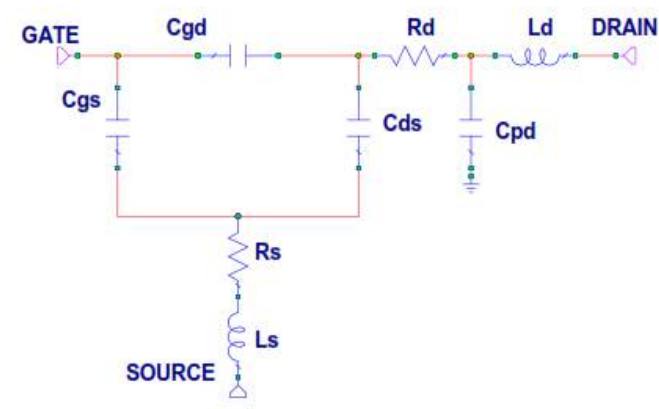

Figure 2. The small signal model of a pHEMT at zero drain bias and gate voltage below pinch-off

The three capacitances $\mathrm{Cg}$, $\mathrm{Cs}$ and $\mathrm{Cd}$ are given by trianglestar transformation as given below

$\mathrm{C}_{\mathrm{g}}=\mathrm{C}_{\mathrm{gs}}+\mathrm{C}_{\mathrm{gd}}+\left[\left(\mathrm{C}_{\mathrm{gs}} * \mathrm{C}_{\mathrm{gd}}\right) / \mathrm{C}_{\mathrm{ds}}\right]$

$\mathrm{C}_{\mathrm{s}}=\mathrm{C}_{\mathrm{gs}}+\mathrm{C}_{\mathrm{ds}}+\left[\left(\mathrm{C}_{\mathrm{gs}} * \mathrm{C}_{\mathrm{ds}}\right) / \mathrm{C}_{\mathrm{gd}}\right]$

$\mathrm{C}_{\mathrm{d}}=\mathrm{C}_{\mathrm{ds}}+\mathrm{C}_{\mathrm{gd}}+\left[\left(\mathrm{C}_{\mathrm{gd}} * \mathrm{C}_{\mathrm{ds}}\right) / \mathrm{C}_{\mathrm{gs}}\right]$ using

Input port and output port impedances can be expressed

$\mathrm{Z}_{11}=\mathrm{R}_{\mathrm{g}}+\mathrm{R}_{\mathrm{s}}+\mathrm{j} *\left[\omega\left(\mathrm{L}_{\mathrm{g}}+\mathrm{L}_{\mathrm{s}}\right)-(1 / \omega)\left\{\left(1 / \mathrm{C}_{\mathrm{g}}\right)+\left(1 / \mathrm{C}_{\mathrm{s}}\right)\right\}\right](4)$

$Z_{22}=R_{d}+R_{s}+j *\left[\omega\left(L_{d}+L_{s}\right)-(1 / \omega)\left\{\left(1 / C_{d}\right)+\left(1 / C_{s}\right)\right\}\right](5)$

Input reflection coefficient and output reflection coefficient

$\Gamma_{\text {in }}=\left(Z_{\text {in }}-Z_{0}\right) /\left(Z_{\text {in }}+Z_{0}\right)$

$\Gamma_{\mathrm{L}}=\left(\mathrm{Z}_{\mathrm{L}}-\mathrm{Z}_{0}\right) /\left(\mathrm{Z}_{\mathrm{L}}+\mathrm{Z}_{0}\right)$

Equivalent input and output impedances can be expressed in terms of two port $\mathrm{Z}$ parameters.

$Z_{\text {in }}=Z_{11}-\left[\left(Z_{12} * Z_{21}\right) /\left(Z_{L}+Z_{22}\right)\right]$

$Z_{\mathrm{L}}=\mathrm{Z}_{22}-\left[\left(\mathrm{Z}_{12} * \mathrm{Z}_{21}\right) /\left(\mathrm{Z}_{\mathrm{G}}+\mathrm{Z}_{11}\right)\right]$

On the premise of the above arrangement numerical conditions unmistakably reliance of $\Gamma$ in and $\Gamma L$ furthermore Zin and $\mathrm{ZL}$ on $\mathrm{Cg}$, $\mathrm{Cs}$ and $\mathrm{Cd}$ which changes because of progress in biasing conditions.

\section{A. Case 1: With Ideal Bias}

Case 1 which incorporates the circuit schematic in figure 3 arranged by using the S-Parameters .S2P documents or mdiff 
files of the transistor ATF36163 from Avago technologies. For the simulations and results got depend on the S-parameters investigation without real biasing circuit (real circuit on PCB format). For this case the matching circuit has been set up to accomplish most ideal consequences of the general circuit regarding GAIN, NF, RL for the total bandwidth from 3$10 \mathrm{GHz}$

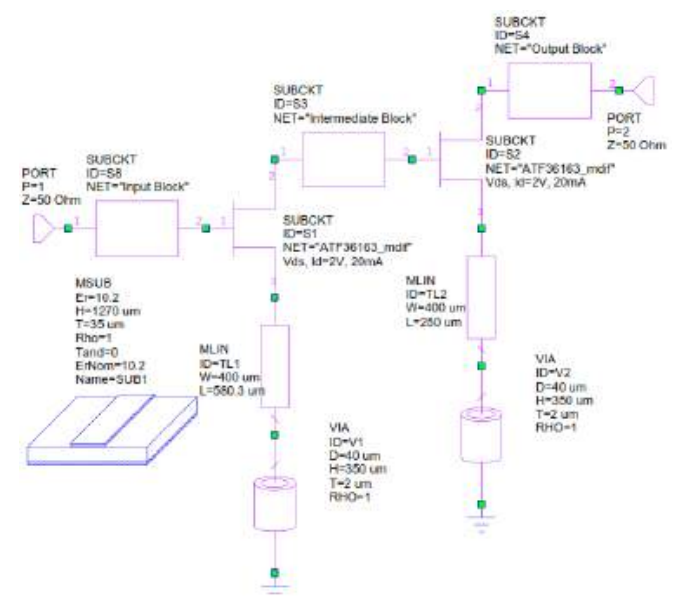

Figure 3. Complete Block

The above figure 3 is of the complete block of the circuit in which it is comprised of three sub blocks called "Input Block" which is displayed in figure 4 in detail, "Intermediate Block" figure 5 and "output block" figure 6. All this blocks are prepared for the best possible results to make transistor to behave has LNA.

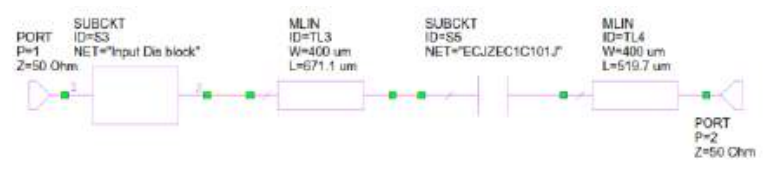

Figure 4. Input Block

The "input block" which is intended for the input matching and mainly it consists of capacitor and one more sub block called "Input Dis Block" which is appeared in figure 7.

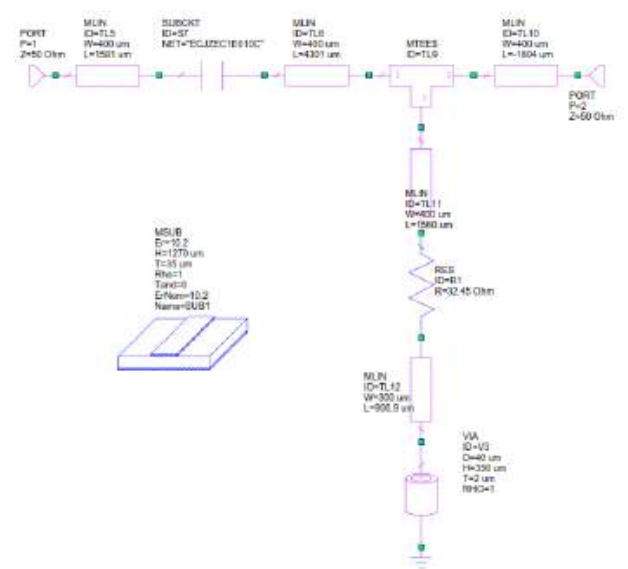

Figure 5. Intermediate Block
The above block figure 5 is designed for intermediate matching between two transistors in cascaded topology.

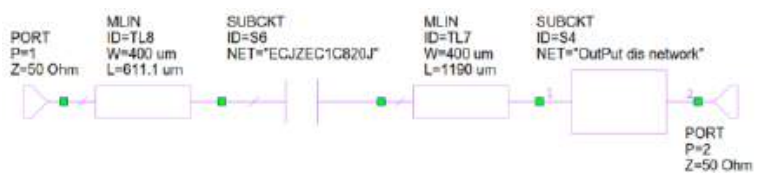

Figure 6. Output Block

The "Output block" figure 6 which is intended for the output matching and mainly it consists of capacitor and one more sub block called "Output Dis Block" which is appeared in figure 8 .

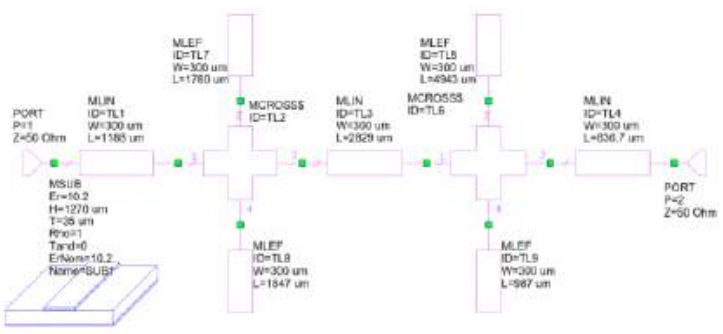

Figure 7. Input Dis block

There are two sub blocks called "Input Dis Block" figure 7 and "Output Dis Block" figure 8 are set up by utilizing just microstrip lines to give great return loss performances at input and output.

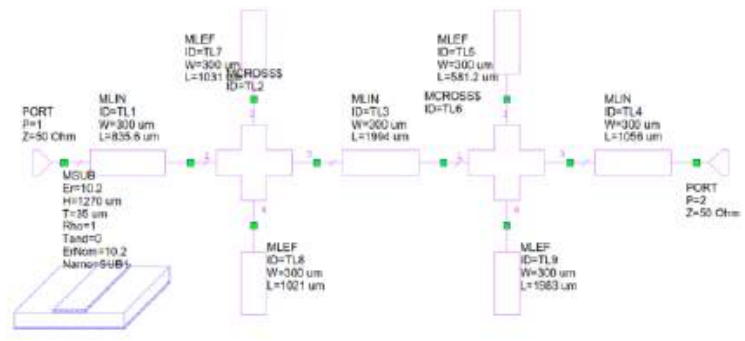

Figure 8. Output Dis network

Case 1 which incorporates the circuit schematic in figure () arranged by using the S-Parameters .S2P documents or mdiff files of the transistor ATF36163 from Avago technologies. For the simulations and results got depend on the S-parameters investigation without real biasing circuit (real circuit on PCB format). For this case the matching circuit has been set up to accomplish most ideal consequences of the general circuit regarding GAIN, NF, RL for the total bandwidth from 3$10 \mathrm{GHz}$. 


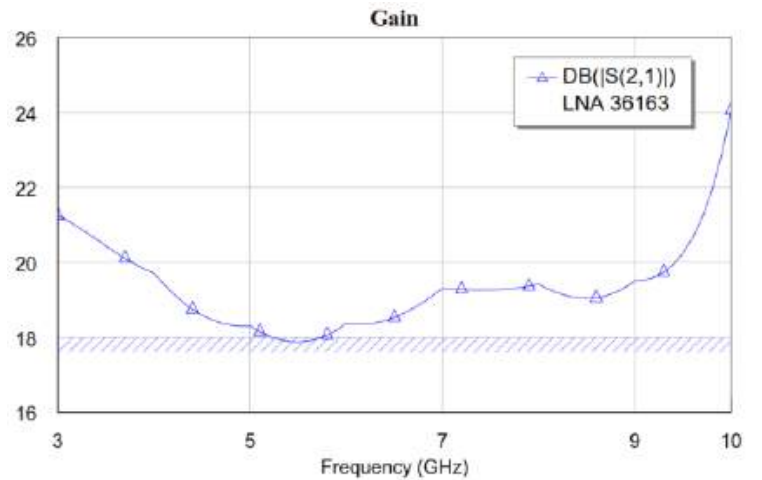

Figure 9. Transducer Gain response over 3-10GHz for the Ideal bias Circuit.

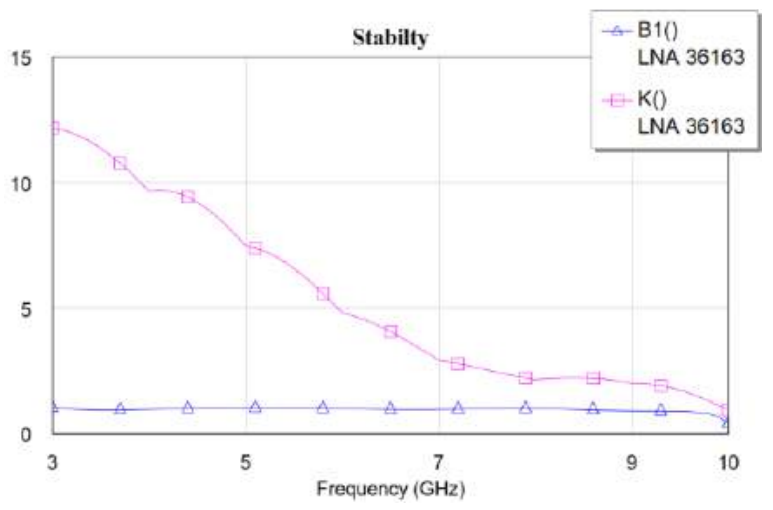

Figure 10. Stability Factors response over 3-10GHz for the Ideal bias Circuit.

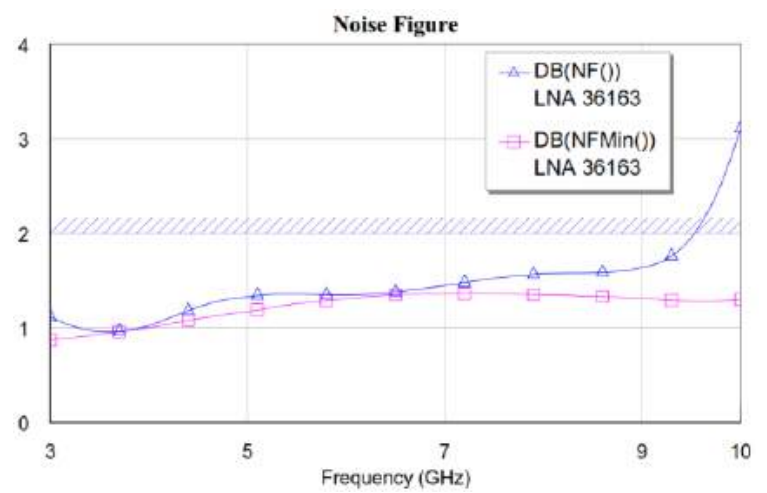

Figure 11. Noise Factors response over 3-10GHz for the Ideal bias Circuit

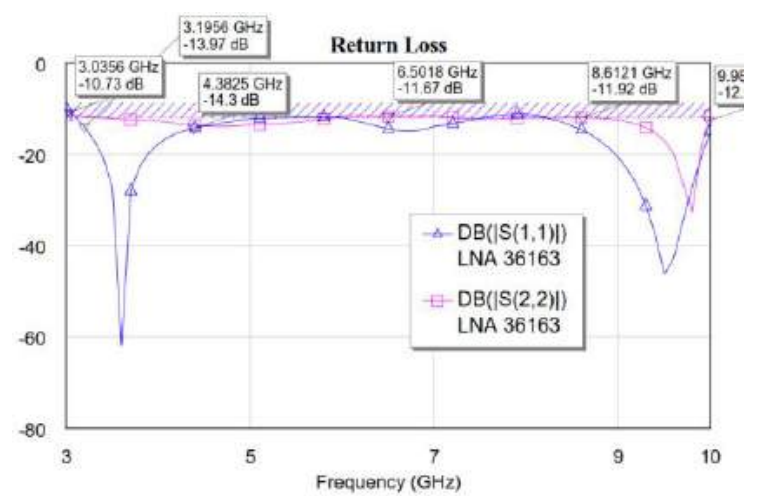

Figure 12. Return Loss response over 3-10GHz for the Ideal bias Circuit
The above simulation results found from the case 1 schematic which is improved to most ideal results concerning return loss satisfying not exactly - $10 \mathrm{~dB}$ with the acquire gain more than $18 \mathrm{~dB}$ and Noise figure under $2 \mathrm{~dB}$.

TABLE I. CHANGE IN LNA PARAMETERS WITH RESPECT TO VARIATION IN IDEAL BIAS POINTS

\begin{tabular}{ccccc}
\hline \hline $\begin{array}{c}\text { Band } \\
\text { width }\end{array}$ & $\begin{array}{c}\text { Bias Points } \\
\text { (VDS, ID) }\end{array}$ & Gain in $\mathrm{dB}$ & $\begin{array}{c}\text { Noise Figure } \\
\text { in } \mathrm{dB}\end{array}$ & $\begin{array}{c}\text { Return Loss } \\
(\mathrm{S} 11, \mathrm{~S} 22) \text { in } \\
\mathrm{dB}\end{array}$ \\
\hline $3-10$ & $1.5 \mathrm{~V}, 10 \mathrm{~mA}$ & $17-20.5$ & $<1.5$ & $<-11,<-12$ \\
$3-10$ & $1.5 \mathrm{~V}, 15 \mathrm{~mA}$ & $17.5-20.8$ & $<1.5$ & $<-11.5,<-13$ \\
$3-10$ & $1.5 \mathrm{~V}, 20 \mathrm{~mA}$ & $17.7-20.9$ & $<1.6$ & $<-11.5,<-13$ \\
$3-10$ & $2 \mathrm{~V}, 10 \mathrm{~mA}$ & $17.4-20.7$ & $<1.531$ & $<-10.5,<-12$ \\
$3-10$ & $2 \mathrm{~V}, 15 \mathrm{~mA}$ & $17.7-21$ & $<1.5$ & $<-11,<-12$ \\
$3-10$ & $2 \mathrm{~V}, 20 \mathrm{~mA}$ & $17.9-21.21$ & $<1.6$ & $<-11,<-13$ \\
\hline \hline
\end{tabular}

The above table portrays the vigour, robustness of the designed circuit, for the varieties of the bias points which has influenced immaterial changes in the Gain, Noise figure and return loss which is plainly depicted in the table.

\section{B. Case 2: with inductive drain bias and resistive gate bias}

For this situation, the biasing circuits are built to a similar circuit which is utilized as a part of case 1 which is inductive drain and resistive bias. Microwave Inductors are used has biasing circuit at Drain as showed up in the above Figure(?). They give high Impedance at designed band frequencies in this way it won't usually give up transducer GAIN. In any case, the biasing circuits will reliably have their resonances. It is essential to plan and enhance the entire LNA design circuit with Inductor equivalent circuit show in order to anticipate the circuit execution is to be exactly.

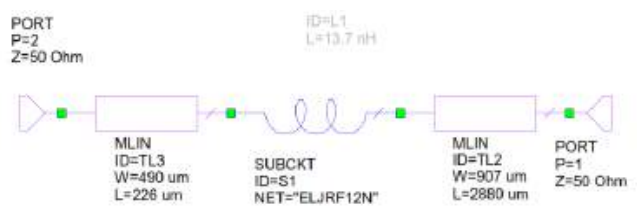

Figure 13. Drain Bias with Inductor

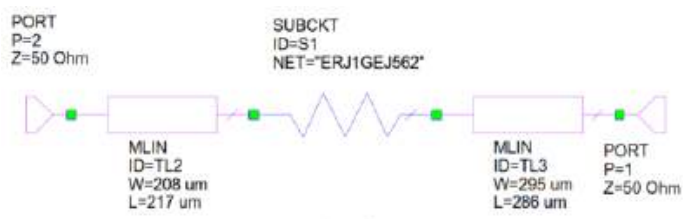

Figure 14. Gate Bias with resistor 


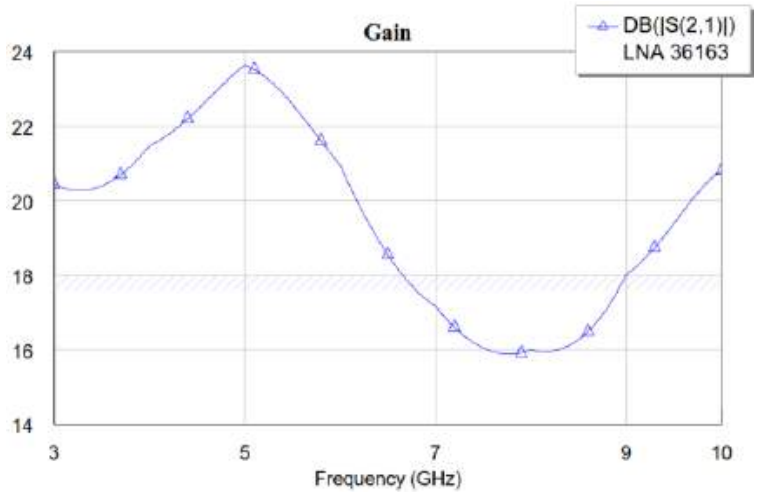

Figure 15. Transducer Gain response over 3-10GHz for the inductive drain bias and resistive gate bias circuit.

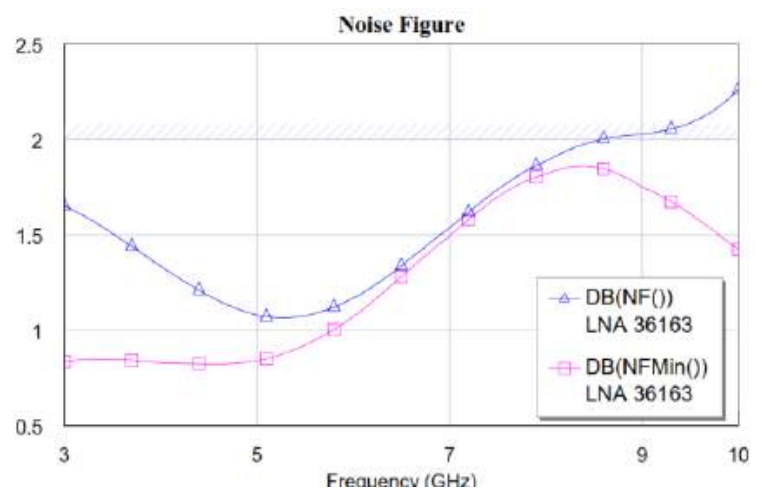

Figure 16. Noise Factors response over 3-10GHz for the inductive drain bias and resistive gate bias circuit.

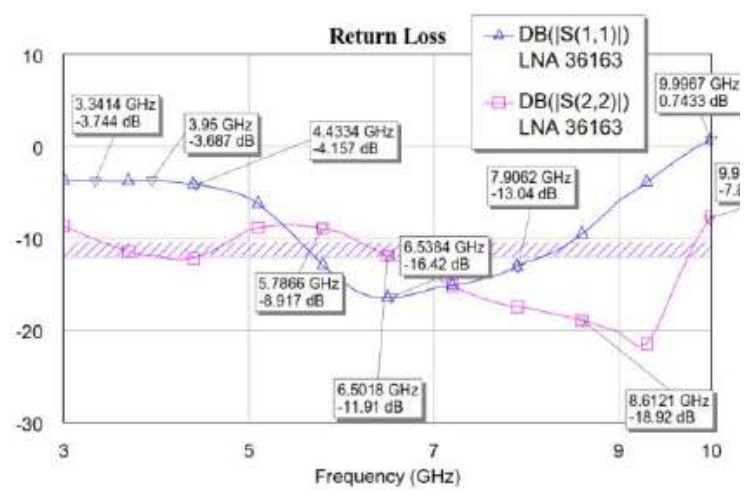

Figure 17. Return Loss response over $3-10 \mathrm{GHz}$ for the inductive drain bias and resistive gate bias circuit

For the same designed circuit for the case 1, by only expansion of the inductive drain and resistive gate bias circuit to has made its own resonance and carried variety of the outcome as for frequency and obviously appeared in the above figures.

TABLE II. CHANGE IN LNA PARAMETERS WITH RESPECT TO VARIATION OF BIAS POINTS FOR INDUCTIVE DRAIN AND RESISTIVE GATE BIAS

\begin{tabular}{cccccc}
\multicolumn{5}{c}{ GATE BIAS } \\
Band & Bias Points & Gain in & Noise & S22) in dB \\
width & (VDS, ID) & $\mathrm{dB}$ & $\begin{array}{c}\text { Figure } \\
\text { in dB }\end{array}$ & S11 in dB & \\
\hline
\end{tabular}

\begin{tabular}{cccccc}
$3-10$ & $1.5 \mathrm{~V}, 10 \mathrm{~mA}$ & $15.5-23$ & $<1.5$ & $<(-3$ to -15$)$ & $<(-9$ to -20$)$ \\
$3-10$ & $1.5 \mathrm{~V}, 15 \mathrm{~mA}$ & $15.9-23.2$ & $<1.5$ & $<(-3.5$ to -15.7$)$ & $<(-9$ to -18$)$ \\
$3-10$ & $1.5 \mathrm{~V}, 20 \mathrm{~mA}$ & $16-23.2$ & $<1.6$ & $<(-3.6$ to -16$)$ & $<(-9$ to -22.5$)$ \\
$3-10$ & $2 \mathrm{~V}, 10 \mathrm{~mA}$ & $15.5-23.4$ & $<1.5$ & $<(-3.6$ to -15$)$ & $<(-9$ to -20$)$ \\
$3-10$ & $2 \mathrm{~V}, 15 \mathrm{~mA}$ & $15.81-23.5$ & $<1.5$ & $<(-3.6$ to -16$)$ & $<(-9$ to -21$)$ \\
$3-10$ & $2 \mathrm{~V}, 20 \mathrm{~mA}$ & $15.92-23.62$ & $<1.6$ & $<(-3.7$ to -16$)$ & $<(-9$ to -21$)$ \\
\hline
\end{tabular}

By the insertion of the inductive drain and resistive gate bias circuit the gain has diminished by $2 \mathrm{~dB}$ and gain flatness additionally got aggravated. Because of resistive gate bias Noise figure got expanded to $2 \mathrm{~dB}$ and discovered return loss some enormous variations and it has been found the circuit bandwidth has decreased to 3-9 GHz.

\section{Case 3: with single pair $L C$}

In this case, biasing circuit is prepared using a set of inductor and capacitor at both drain and gate side. Each extra Inductance with parasitic (resistance, capacitance) in arrangement with the capacitor grounded, whether of parasitic source" inside" the capacitor brought about by design or development, diminishes the adequacy of the bias circuit. The pair of LC circuits creates its own resonance and disturbs LNA parameters. Long connections between the capacitor and ground are extra undesirable arrangement inductance regardless of to whether the inductance originates from the interfacing legs of the capacitor, the conductor tracks or dashes on the component group installation. Designers and layout specialists are regularly confronted with apparently practically insoluble issues in such manner, as limitations, for example, the space accessibility inside the component group and so on.

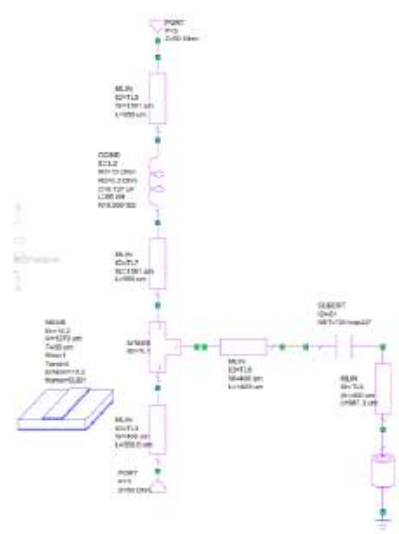

Figure 18. Drain Bias

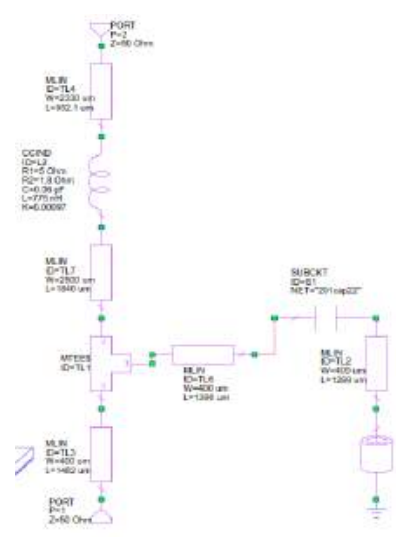

Figure 19. Gate Bias 


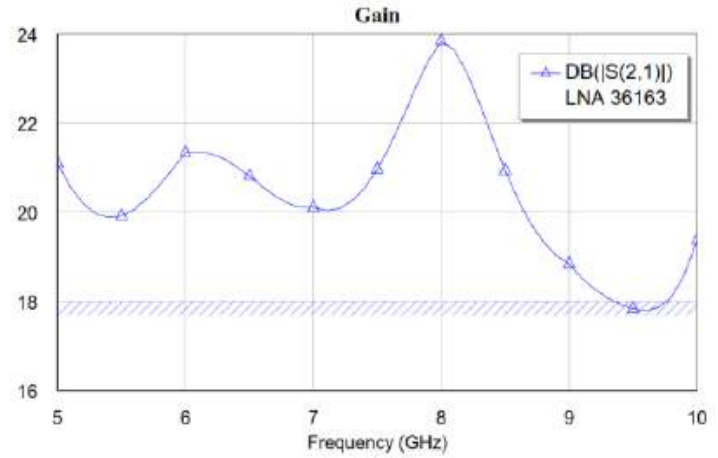

Figure 20. Gain response over $5-10 \mathrm{GHz}$ for the single pair LC bias circuit

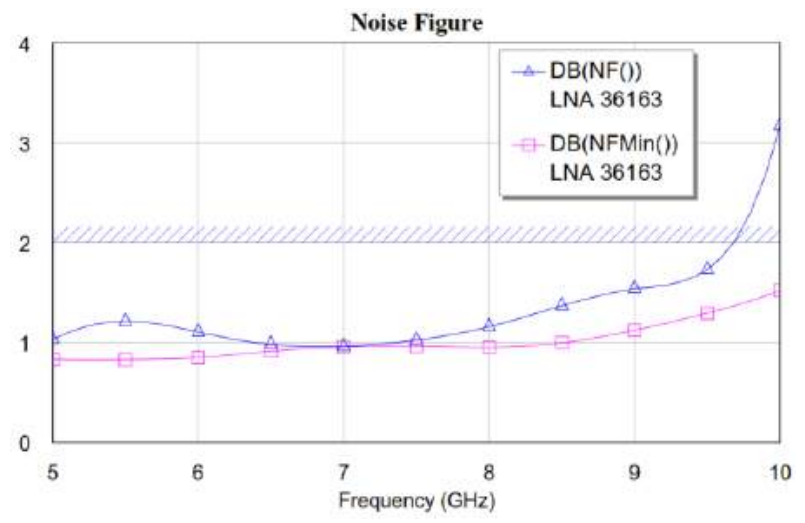

Figure 21. Noise Figure response over $5-10 \mathrm{GHz}$ for the single pair LC bias circuit

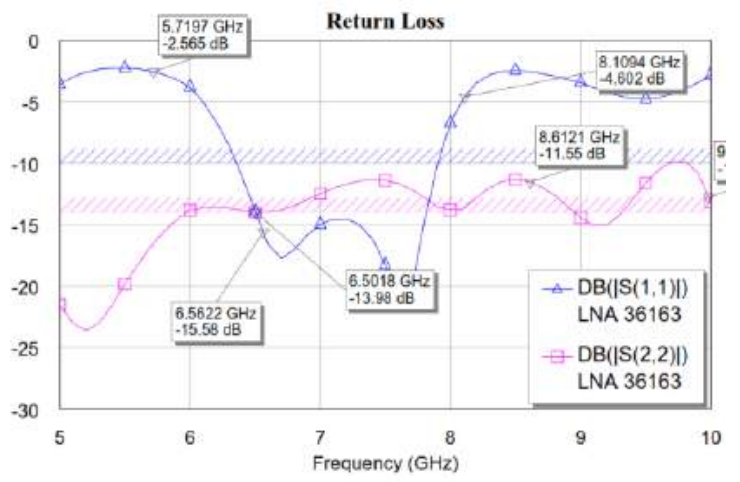

Figure 22. Return Loss response over 5-10GHz for the single pair LC bias circuit

the above simulated results are from case 3 circuit which has not affected gain or noise figure but created the resonance and disturbed the input return loss in its own band between 6$8 \mathrm{GHz}$.

TABLE III. CHANGE IN LNA PARAMETERS WITH RESPECT TO VARIATION OF BIAS POINTS FOR LC BIASING CIRCUIT

\begin{tabular}{cccccc}
\hline \hline $\begin{array}{c}\text { Band } \\
\text { widt } \\
\mathrm{h}\end{array}$ & $\begin{array}{c}\text { Bias Points } \\
\text { (VDS(V), }\end{array}$ & $\begin{array}{c}\text { Gain in } \\
\mathrm{dB}\end{array}$ & $\begin{array}{c}\text { Noise } \\
\text { Figure } \\
\text { in } \mathrm{dB}\end{array}$ & $\mathrm{S} 11$ in $\mathrm{dB}$ & $\begin{array}{c}\text { S22) in } \\
\mathrm{dB}\end{array}$ \\
\hline $3-10$ & $1.5,10$ & $16.8-23$ & $<1.5$ & $<-2.8$ to -20 & $<-11$ to -20 \\
$3-10$ & $1.5,15$ & $17.5-23$ & $<1.5$ & $<-2.7$ to -20 & $<-11$ to -23 \\
$3-10$ & $1.5,20$ & $17.7-23$ & $<1.5$ & $<-2.6$ to -22 & $<-11$ to -23
\end{tabular}

$3-10 \quad 2,10 \quad 17-23.5<1.4<-2.7$ to $-20<-11$ to -23

$3-10 \quad 2,15 \quad 17.5-23.7<1.4<-2.6$ to $-21<-11$ to -23

$3-10 \quad 2,20 \quad 17.8-23.7<1.4<-2.6$ to $-21<-11$ to -23

the above table describes the variations of the parameters with respect to the different biasing points. It is observed the best result found for this case at bias point $2 \mathrm{~V}, 20 \mathrm{~mA}$.

\section{Case 4: with double pair LC}

In this case 4 which is designed for the same case 1 circuit by adding double pair LC at both drain and gate of the transistors. This case is prepared to show the double LC pair will creates its own resonance with increase in the bandwidth. Only biasing circuit will be optimized to best result possible.

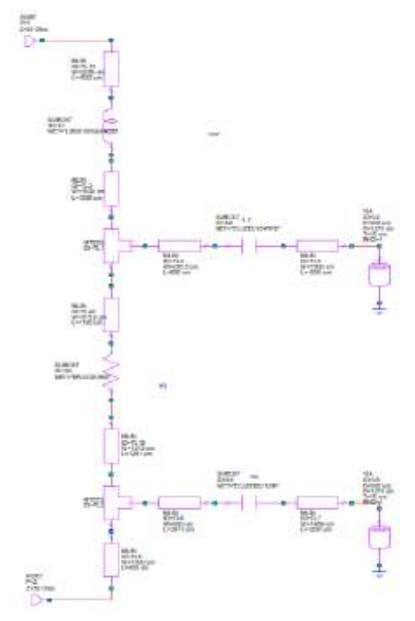

Figure 23. Drain Bias

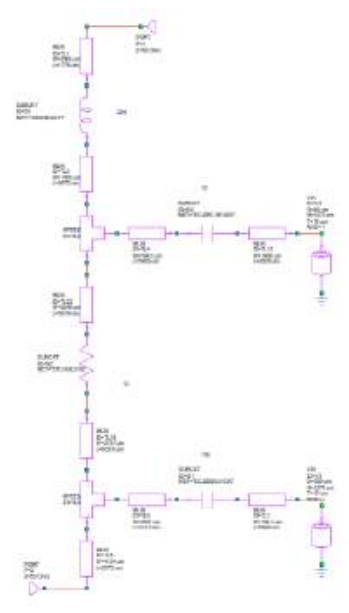

Figure 24. Gate Bias

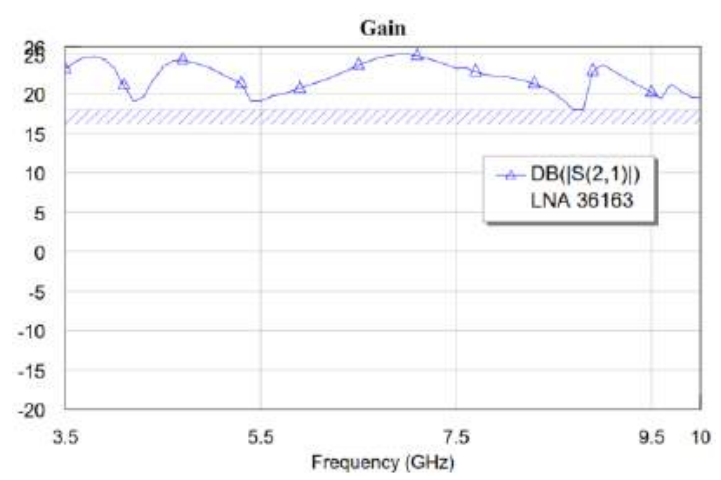

Figure 25. Gain response over 3.5-10GHz for the double pair LC bias circuit 


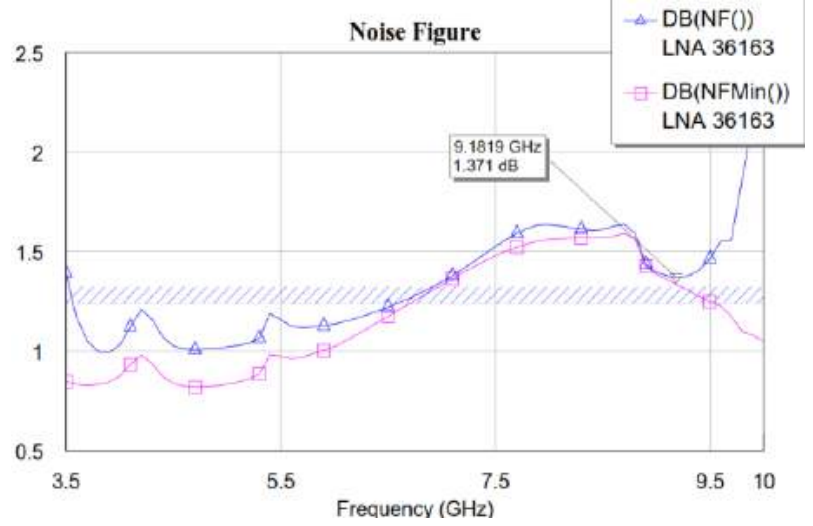

Figure 26. Noise Figure response over 3.5-10GHz for the double pair LC bias circuit

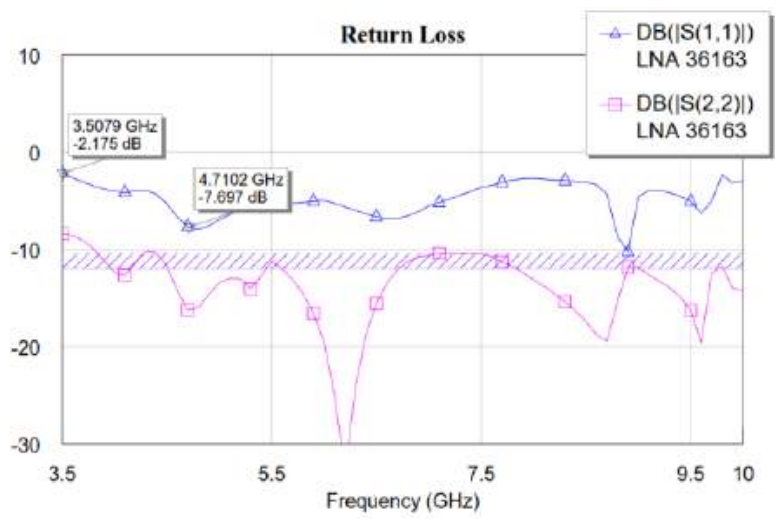

Figure 27. Return Loss response over 3.5-10GHz for the double pair LC bias circuit

By using double pair LC as biasing circuit has improved gain and input return loss with minor increase of noise figure.

TABLE IV. CHANGE IN LNA PARAMETERS WITH RESPECT TO VARIATION OF BIAS POINTS FOR DOUBLE BIASING CIRCUITS

\begin{tabular}{cccccc}
\hline \hline $\begin{array}{c}\text { Band } \\
\text { widt } \\
\mathrm{h}\end{array}$ & $\begin{array}{c}\text { Bias Points } \\
\text { (VDS(V), } \\
\text { ID(MA)) }\end{array}$ & $\begin{array}{c}\text { Gain in } \\
\mathrm{dB}\end{array}$ & $\begin{array}{c}\text { Noise } \\
\text { Figure } \\
\text { in } \mathrm{dB}\end{array}$ & S11 in dB & $\begin{array}{c}\text { S22) in } \\
\mathrm{dB}\end{array}$ \\
\hline $3-10$ & $1.5,10$ & $16.8-23$ & $<1.6$ & $<-1.7$ to -10 & $<-9$ to -20 \\
$3-10$ & $1.5,15$ & $17.5-23$ & $<1.6$ & $<-1.8$ to -10 & $<-9$ to -20 \\
$3-10$ & $1.5,20$ & $17.7-23$ & $<1.6$ & $<-2$ to -10 & $<-9$ to -20 \\
$3-10$ & 2,10 & $17-23.5$ & $<1.6$ & $<-2$ to -10 & $<-9$ to -20 \\
$3-10$ & 2,15 & $17.5-23.7$ & $<1.5$ & $<-2$ to -10 & $<-9$ to -20 \\
$3-10$ & 2,20 & $17.8-23.7$ & $<1.6$ & $<-2$ to -10 & $<-9$ to -20 \\
\hline \hline
\end{tabular}

\section{BIASING CiRCUIT EFFECTS ON NON-LINEAR CHARACTERISTICS}

In this section, illustrations and clarifications of LNA Design Circuit as for biasing Circuit will be given. [15-16] The effects of Biasing circuit are explained by insertion of single tone sinusoidal voltage wave $(\mathrm{V} \sin (\omega \mathrm{t}))$ to the non-signal voltage results in

$\mathrm{v}_{\mathrm{gs}}=\mathrm{V}_{\mathrm{GSQ}}+\mathrm{V} \sin (\omega \mathrm{t})$

vgs will be the function of $\mathrm{Vds}$ and Id biasing point of the transistor which has already been tabulated for the multiple cases and discussed. Then the harmonic distortion KF is

$$
\begin{gathered}
K F=\frac{\text { Relative value of second harmonics }}{\text { Relative value of fundamental harmonics }} \\
\qquad K F=\frac{V}{4(V g s-V p)}
\end{gathered}
$$

Where $\mathrm{V}$ is maximum amplitude of the signal.

Noted: Distortion Factor approaches to its minimum as $\mathrm{Vgs}$ tends to 0

Cross modulation (Intermodulation) produced when two sine wave signals are amplified at the same time.

$\mathrm{v}_{\mathrm{gs}}=\mathrm{V}_{\mathrm{GSQ}}+\mathrm{V}_{1} \sin (\omega \mathrm{t})+\mathrm{V}_{2} \sin (\omega \mathrm{t})$

Since the output current includes the sum and difference components of the two sinusoidal waves in which intermodulation results in

$$
\begin{gathered}
I M=\frac{\text { Relative value of cross modulation components }}{\text { Relative value of fundamental harmonics }} \\
I M=\frac{V_{1} * V_{2}}{\sqrt{2}\left(V_{G S Q}-V_{p}\right)\left(\sqrt{V_{1}^{2}+V_{2}^{2}}\right.}
\end{gathered}
$$

In this case, also it has been clearly examined that distortion factor decreases as bias is brought closer to $V_{G S O}=0$. These twodistortion factor will exist in biased circuit which will deteriorate performance of the designed circuit.

\section{SUMMARY}

The experimented results of this work can be summarized as following in the preferences of cases:

Case1: Ideal Bias LNA circuit intended for the best reasonable estimations of Gain, NF and Bandwidth (3-10GHz) which is utilized to correlate for the remaining three biasing strategies likely Drain Inductance and gate resistance bias, LC bias and double LC bias.

Case 2: Drain Inductance and gate resistance bias is recommended for the LNA design whose bandwidth is up to $4 \mathrm{GHz}$. The performance in this case linearly Gain decrease and NF increases and stability will not be affected at any cost.

Case 3: LC bias is suggested for the LNA design for the smaller bandwidth generally around $2 \mathrm{GHz}$. The LNA performance with respect to Gain and NF will be great and results will keep up flatness over small bandwidth.

Case 4: Double LC is proposed for the wideband and ultraband with the viable cost on return loss, Gain and NF won't be highly influenced.

\section{A. Confinement of the Biasing Circuit Design}

1) the main cause of the distortion or the variations of the results with various cases of the biasing circuit is the nonlinearity in the transfer characteristics of the overall circuit with micro strip line

2) Distortion is also caused by the output conductance $\mathrm{gd}$ related to operating point and drain voltage Vds. 


\section{B. Conceivable Solution}

1) By applying the feedback to the circuit both distortion factor and bandwidth can be improved.

2) It is possible to have wideband amplifier with low distortion factor by initially designing the amplifier for the high gain and tuning the gain to its optimum level by using feedback.

\section{CONCLUSION}

In this work the effect of biasing circuit on LNA performance. The effect of three different biasing strategies, namely; Drain Inductance and gate resistance bias, LC bias and double LC bias are compared with the ideal bias characteristics of the LNA design. The parameters in each of these approached are re-enacted, Simulated and optimized in AWR microwave office. The importance of the biasing techniques as far as bandwidth, Noise Figure, Gain and return Loss. Every case has been breaking down with criticalness of the segments utilized as a part of analysis in component level of the design and corresponding impacts on overall circuit have been introduced. This work is expected to contribute in LNAs for satellite communications transmissions, Wi-Fi devices and weather radar systems.

The proposed work given examination, comparison of different biasing techniques and also clarified with small signal equivalent circuit model. Moreover, it is obviously presumed that LNA performances is altogether influenced by the biasing circuit strategies. The authors are extended their clear reasonable view and summarized about the effects of different biasing strategies as for BW, Gain and NF.

\section{ACKNOWLEDGMENT}

The authors would like to wish recognize the support for MCT's Rajiv Gandhi Institute of Technology, Mumbai furthermore authors want to express gratitude towards Dr. Udhav Bhosle, Principal of RGIT, for huge support and consolation for this research work. The authors want to exceptional a debt of gratitude is in order for Dr. Krishna Venkatesh, Prof. K. T Srirangaraj, Dr. TGS Moorthy, Prof. Chandrashekar K. CET, Jain University, Bangalore and Mr. Manjunatha Reddy $\mathrm{H}$. V General Manager, RF and $\mu \mathrm{W}$ division, Icon Design Automation Pvt. Ltd. for their significant guidance and support.

\section{REFERENCES}

[1] Michael Steer, "Microwave and RF Design: A Systems Approach," in SciTech Pub., 2010 - Technology \& Engineering. 952 pages.

[2] David M.Pozar, "Microwave Engineering", 3Rd Ed in John Wiley \& Sons, 01-Sep-2009 - Microwave circuits - 728 pages.

[3] Reinhold Ludwig, Gene Bogdanov, "RF Circuit Design: Theory and Applications" in Prentice Hall, 2009 - Technology \& Engineering - 704 pages

[4] Joseph J. Carr, "Secrets of RF Circuit Design", Volume 3, Mcgraw-hill, 11-Dec-2000 - Technology \& Engineering - 544 pages.

[5] Nguyen, P. T., Phan, L., Nguyen, Tuan, Tran, Van-Su, ... P.M., C. (2015). X-band TR Module for Radar and Wireless Communication
Systems. International Conference on Advanced Technologies for Communications (ATC) 978-1-4673-8374-5/15/\$31.00 @2015 IEEE, 183-187.

[6] Taryana, Y., Sulaeman, Y., Wahyu, Y., Armi, N., Paramayudha, K., \& Rojak, R. A. (2015). Design of Two Stage Low Noise Amplifier Using Double Stub Matching Network. IEEE International Conference on Aerospace Electronics and Remote Sensing Technology (ICARES).

[7] Fernandes, M. D., Oliveira, L. B., \& Goes, J. (2016). Wideband noise cancelling balun LNA with feedback biasing,. IEEE International Symposium on Circuits and Systems (ISCAS), Montreal, QC, Canada doi: 10.1109/ISCAS.2016.7527226, 285-288.

[8] Gecan, D., Olavsbråten, M., \& Gjertsen, K. M. (2016). Measured linearity improvement of $10 \mathrm{~W}$ GaN HEMT PA with dynamic gate biasing technique for flat transfer phase. IEEE MTT-S International Microwave Symposium (IMS), San Francisco, CA, USA doi: 10.1109/MWSYM.2016.7540309, 1-4

[9] Zhang, D., Ma, H., Yu, H., \& Li, J. (2016). Design and on-wafer measurements of $60 \mathrm{GHz}$ MMIC LNA with on-chip active biasing. IEEE International Workshop on Electromagnetics: Applications and Student Innovation Competition (iWEM), Nanjing,doi: 10.1109/iWEM.2016.7504894, 1-3.

[10] Ghosh, S., \& Srivastava, K. V. (2016). Polarization-Insensitive Singleand Broadband Switchable Absorber/Reflector and Its Realization Using a Novel Biasing Technique. IEEE Transactions on Antennas and Propagation, vol. 64, no. 8, 3665-3670.

[11] Harzheim, T., Heuermann, H., \& M. Marso. (2016). An adaptive biasing method for SRD comb generators. German Microwave Conference (GeMiC), Bochum doi: 10.1109/GEMIC.2016.7461613, 289-292.

[12] A. Iftikhar et al., "A printed dipole reconfigured with magneto-static responsive structures that do not require a directly connected biasing circuit," 2016 IEEE International Symposium on Antennas and Propagation (APSURSI), Fajardo, 2016, pp. 1057-1058. doi: 10.1109/APS.2016.7696236.

[13] J. M. Dores, E. B. Alvarez, M. A. Martins, J. M. de la Rosa and J. R. Fernandes, "A comparative study of biasing circuits for an inductorless wideband Low Noise Amplifier," 2011 IEEE 54th International Midwest Symposium on Circuits and Systems (MWSCAS), Seoul, 2011, pp. 14.doi: 10.1109/MWSCAS.2011.6026435

[14] Y. S. Noh, D. P. Chang and I. B. Yom, "Ku-band high-power amplifier MMIC with on-chip gate biasing circuit," in Electronics Letters, vol. 45 no. 15, pp. 794-795, July 16 2009. doi: 10.1049/el.2009.0251

[15] H. G. Han, D. H. Jung and T. W. Kim, "A $2.88 \mathrm{~mW}+9.06 \mathrm{dBm}$ IIP3 Common-Gate LNA With Dual Cross-Coupled Capacitive Feedback," in IEEE Transactions on Microwave Theory and Techniques, vol. 63, no. 3, pp. 1019-1025, March 2015. doi: 10.1109/TMTT.2014.2377036

[16] H. Lee, T. Chung, H. Seo, I. Choi and B. Kim, "A Wideband Differential Low-Noise-Amplifier With IM3 Harmonics and Noise Canceling," in IEEE Microwave and Wireless Components Letters, vol. 25, no. 1, pp. 46-48, Jan. 2015. doi: 10.1109/LMWC.2014.2365733

\section{AUTHORS PROFILE}

K. G. Sawarkar is working towards Ph.D. as Research Scholar at MCT's Rajiv Gandhi Institute of technology, Mumbai University. Currently working as Head of Electronics \& Telecommunication Engg Dept. RGIT, Mumbai and. His Area of Interest is Design of analog circuits, design of RF circuits and systems $\mathrm{He}$ has done his $\mathrm{BE}$ in Electronics under Amravati University and M.E from Mumbai University. 
Dr. Kushal R. Tuckley is currently working as Adjunct Professor, IIT Bombay, also Chairman and Director R\&D, AGV Systems Pvt.Ltd. His research area interest Radars, Microwave systems and wireless Industrial instrumentation. $\mathrm{He}$ has B. Tech, M.Tech and $\mathrm{PhD}$ from IIT Bombay. He had a 25 years long career as a scientist in Society for Applied Microwave Electronics Engineering and

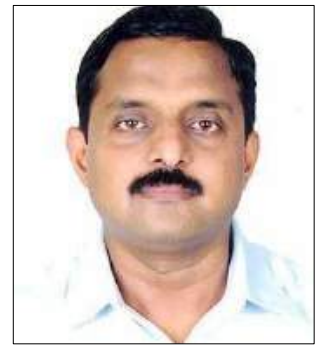
Research (SAMEER), a premium research institute in microwave systems engineering. He has significant contribution in many of the prestigious projects commissioned by the Govt. of India. He had a stint at Astra Microwave Products Ltd.

Mr. Pramod K B was born in Mysore, Karnataka, India in $1989 . \mathrm{He}$ is currently working as Assistant Professor in MCT's RGIT, Mumbai and also working towards $\mathrm{PhD}$ degree at JAIN University, Bangalore in Electronics Engineering. He received his B.E degree in Electronics and Communication from Dr.Ambedkar Institute of Technology, Bangalore Visvesvaraya Technological University in 2010, M.Tech degree in

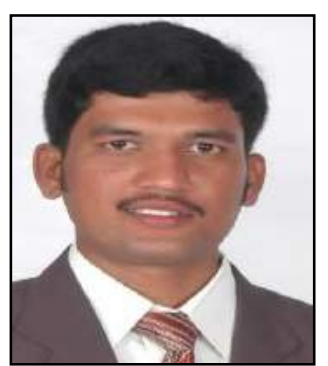

R F Communication from Jain University, Bangalore, in 2012 and $\mathrm{He}$ worked as R F Design trainee at Icon Design and Automation Pvt Ltd and as visiting research scholar at University of Concordia, Montreal, Quebec, Canada. His research includes Design, Characterization And Optimization Of RF Passive Devices, Board Level Tuning And Optimization Of Matching Networks, Low Noise Amplifier, Power Amplifier, Circuit Linearization And High-Efficiency Design Techniques, Circuit Instability and Strategies.

Prof. Dr. Kumaraswamy H.V is currently working as Professor \& HOD in the Dept of Telecommunication Engineering, RVCE, and Bangalore. His research interests are Digital Signal Processing, Adaptive Signal Processing and Communication. He has got PhD from Visvesvaraya Technological University for the research work on Smart Antenna System using Dielectric lens. He is the author of the book titled "Signals \& Systems" Published by: SciTech Publication, Chennai, ISB No.8188429260.

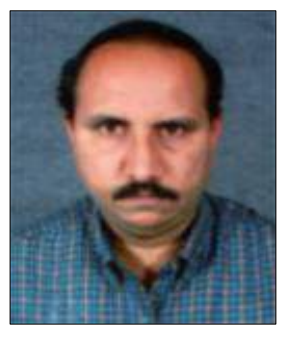

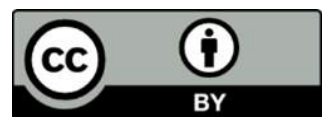

(C) 2017 by the author(s); licensee Empirical Research Press Ltd. United Kingdom. This is an open access article distributed under the terms and conditions of the Creative Commons by Attribution (CC-BY) license. (http://creativecommons.org/licenses/by/4.0/). 